\title{
PHYSICAL, PHYSIOLOGICAL AND PSYCHOLOGICAL FITNESS OF INDEPENDENT ACTIVE AND NON-ACTIVE OLDER FEMALE ADULTS
}

\author{
Rebeka Prosoli, Lovro Štefan, Renata Barić, Goran Sporiš \\ University of Zagreb, Zagreb, Croatia
}

\begin{abstract}
Background. Aging represents period of life when human body undergoes great changes affecting people's condition and overall health. The aim of the research was to determine differences of motor and functional abilities along with satisfaction and quality of life between active and non-active female older adults.

Methods. Twenty-one elderly female adults were classified in two groups: thirteen active (mean age $66.54 \pm$ 4.59 years; mean height $158.08 \pm 5.35 \mathrm{~cm}$; mean weight $75.47 \pm 13.52 \mathrm{~kg}$; mean body mass index $30.18 \pm 0.49 \mathrm{~kg} / \mathrm{m}^{2}$ ) and eight non-active (mean age $71.81 \pm 7.15$ years; mean height $160.55 \pm 6.34 \mathrm{~cm}$; mean weight $74.40 \pm 14.06 \mathrm{~kg}$; mean body mass index $28.84 \pm 0.35 \mathrm{~kg} / \mathrm{m}^{2}$ ) female adults. For the purpose of this study, all participants were asked to complete senior fitness test protocol prescribed by Rikli and Jones (2013), which consisted of eight tests: 30-second chair stand test, 30-second arm curl test, 2-minute step test, chair sit-and-reach test, back scratch test, 8-foot up-andgo test, height and weight. Along with that, participants filled in Croatian version of WHOQOL-BREF questionnaire (Pibernik-Okanović, 2001) including four domains (physical health, psychological health, social environment and environment) with two additional questions about their satisfaction with health and their quality of life on the Likert scale ranging from 1to 5 . The differences between active and non-active groups were examined using Man-Witney $U$-test. Significance was set at $p<.05$.

Results. Results showed significant differences in four fitness tests: 30-second arm curl test ( $p=.03$ ), 2-minute step test $(p=.00)$, chair sit-and-reach test $(p=.02), 8$-foot up-and-go test $(p=.01)$ and two questionnaire domains: psychological health $(p=.04)$ and environment $(p=.01)$. No statistical differences were found among perception of the quality of life and health satisfaction between non-active and active participants $(p>.05)$.

Conclusion. This study showed that older female adults had better achievements in motor and psychological tests, which could be translated to better physical overall fitness and preparedness of doing everyday activities in comparison to non-active group. Research showed the importance of exercising in older age, but further studies on bigger samples need to be performed for better understanding of aging and differences in levels of fitness.
\end{abstract}

Keywords: geriatrics, conditioning abilities, satisfaction with life, aging.

\section{INTRODUCTION}

$\mathrm{T}$ The aging process is of course a biological reality which has its own dynamics, largely beyond human control. However, it is also subject to the constructions by which each society makes sense of old age. In the developed world, chronological time plays a paramount role. The age of 60 or 65 roughly equivalent to retirement ages in most developed countries is said to be the beginning of old age (Gorman, 1999). According to Nelson et al. (2007), in future several decades, the world population is predicted to face a large increase in proportion of older adults. Because of that older individuals experience impairments and disabilities in overall functioning, especially increasing incidence of chronic health problems, like cardiovacular diseases and osteoporosis. Statistics suggest that many older people do not get the amount of exercise they need and that 
$42 \%$ of those over 65 are experiencing functional limitations in common everyday activities. Those numbers have not improved over the past decade (Federal Interagency Forum on Aging-Related Statistics, 2010). As a result, although average life expectancy continues to increase, so does the possibility of living more years with physical limitations. Many older adults, often because of their sedentary lifestyles, are functioning dangerously close to their maximum ability during normal activities of daily living (Rikli \& Jones, 2013). One of the best ways for preventing such conditions is physical activity. In elderly, it is important for physical functioning and allows performance of more integrated functional tasks (Dipietro, 1996). Longitudinal studies have reported that physical activity improves survival (Bath \& Morgan, 1998; Blair \& Wei, 2000; Glass, Mendes de Leon, Marottoli, \& Berkman, 1999; Simonsick et al., 1993) and functional abilities (Blair \& Wei, 2000), such as muscle strength and power, balance, flexibility, endurance and mobility (Taylor et al., 2004). Surgeon General's report of 1996 encourages all adults to participate in 30 minutes of moderate physical activity in most days of the week (i.e. $\geq 5$ days a week). Although physical activity has positive impact on physical and physiological functioning, evidence is also emerging for its positive effects on mental health, more specific the quality of life (QOL).In mainstream psychology, quality of life is defined as a conscious cognitive judgment of satisfaction with one's life (Pavot \& Diener, 1993).It refers to behavioral functioning or the ability not only "to do" stuff but also live long enough to do it (Kaplan, 1994) and reflects the perceived degree to which individuals are able to satisfy their psychophysiological needs (Berger, Pargman \& Weinberg, 2007). Old population often deal with psychological disabilities, which are defined as any disturbance in the capacity to perform a mental activity considered normal for a human being (Fougeyrollas et al., 1998). They have been associated with participation restriction (Desrosier et al., 2004), social isolation (Charmaz, 1983) and depression (Horowitz, Reinhardt, Boerner, \& Travis, 2003). It is agreed that wellbeing, considered as the way people see and feel about their lives, is a multifaceted phenomenon (Gauvin \& Spence, 1996), especially in the aging population (Spirduso \& Cronin, 2001). Rejeski and Mihalko (2001) have concluded that physical activity can improve health-related quality of life. Moreover, the effect of a physical activity may be moderate considering the functional ability in a person's life. Maintaining the health of older people is therefore of increasing importance to public health.

The aim of the present study was to investigate differences in physical, physiological and phychological parameters between active and nonactive older female adults who were independent.

\section{METHODS}

Participants. The sample consisted of twentyone elderly female adults living independently, classified in two groups. The first group included 13 healthy, active female adults (mean age $66.54 \pm$ 4.59 years; mean height $158.08 \pm 5.35 \mathrm{~cm}$; mean weight $75.47 \pm 13.52 \mathrm{~kg}$; mean body mass index $30.18 \pm 0.49 \mathrm{~kg} / \mathrm{m}^{2}$ ) and second group of eight healthy, but non-active female adults (mean age $71.81 \pm 7.15$ years; mean height $160.55 \pm 6.34 \mathrm{~cm}$; mean weight $74.40 \pm 14.06 \mathrm{~kg}$; mean body mass index $28.84 \pm 0.35 \mathrm{~kg} / \mathrm{m}^{2}$ ). The term "active" means doing organised physical activity minimum twice a week for one hour and "non-active" - that adults do not participate in any kind of organised physical activity. Participation in the study was voluntary, and each of the participants could withdraw from the study at any time.

Procedure. In the beginning, twenty-one participants participated in the study and everyone completed Senior Fitness Test (SFT) along with WHOQOL-BREF questionnaire. No participants suffered from any kind of chronic disease and met the criteria. One expert filled in the questionnaire with each subject separately (only read the questions and circled the numbers on Likert scale), while the second expert first demonstrated and explained each test separately and then measured SFT prescribed by Rikli and Jones (2013). The testing protocol was held between 17:00-19:00 p.m. because their cardiac rhythms should not be disturbed, and the air temperature ranged from 22 to $26^{\circ} \mathrm{C}$.

Anthropometric measures. Anthropometric variables were measured according to the guidelines of the International Biological Program. Body height was measured to the nearest $0.1 \mathrm{~cm}$ by the anthropometric equipment called anthropometer. Body weight was measured to the nearest $0.01 \mathrm{~kg}$ using a digital scale. Body mass index (BMI) was calculated using the formula BMI = body mass $(\mathrm{kg}) /(\text { body height }[\mathrm{m}])^{2}$. 
Senior Fitness Test (SFT). Senior Fitness Test (SFT) is used to assess physical fitness in older adults across a wide range of groups and ability levels. For a fitness test to be appropriate for older adults, it must reflect the major physical parameters associated with functional mobility and be safe and feasible for use in the field settings. (1) The first test was called " 30 -second chair stand test" and it was used to assess lower body strength. The test involved counting the number of times, within a 30 -second period, that a person could come to a full stand from a seated position with arms folded across the chest. This test showed great intraclass correlation $(I C C=.89$ for all participants; $I C C=.86$ for men and $I C C=.92$ for women). (2) 30 -second arm curl represented the second test as a general measure of upper-body strength. The test involved counting the number of times a person could curl a hand weight, more specific 5 pounds $(2.3 \mathrm{~kg})$ for women and 8 pounds $(3.6 \mathrm{~kg})$ for men, through the full range of motion in 30 seconds. Test-retest also showed great intraclass correlation for all participants $(I C C=.81 ; I C C=.81$ for men and $I C C=.80$ for women). (3) Next was 2-minute step test as an alternative measure of aerobic endurance when space limitations prohibited the use of the 6-minute walk test. The whole protocol involved determining the number of times in 2 minutes that a person could step in place, raising the knees to a height halfway between the patella (knee cap) and iliac crest (front hip bone). Intraclass correlation showed great reliability between test-retest $(I C C=$ .90 for all participants; $I C C=.90$ for men and $I C C=.89$ for women). (4) The purpose of the chair sit-and-reach test was to assess lower-body flexibility, particularly hamstring flexibility, which is important for good posture and mobility. The test involved sitting at the front edge of a stable chair with one leg extended and the other foot flat on the floor. With hands on top of each other and arms outstretched, the participant reached as far forward as possible toward the toes. The score is the number of inches (in our case centimetres), either plus or minus, between the tips of the middle fingers and the toes. The test was measured two times in our study to see significance between measures. Speaking about significance, this test showed very good intraclass correlation within all participants $(I C C=.95 ; I C C=.92$ for men and $I C C=.96$ for women). (5)The purpose of the back scratch test was to assess upper-body flexibility, particularly shoulder flexibility. The test involved reaching one hand over the shoulder and down the back as far as possible and the other hand around the waist and up the middle of the back as far as possible, trying to bring the fingers of both hands together. The score is the number of inches (for us centimetres), either plus or minus, between the extended middle fingers. The test was measured two times in our study. Test-retest significance showed great intraclass correlation $(I C C=.96$ for all participants; $I C C=.96$ for men and $I C C=$ .92 for women). (6) 8-foot up-and-go test had the purpose to assess agility and dynamic balance. The test involved getting up from a seated position and walking as quickly as possible around the cone that is 8 feet $(2.4 \mathrm{~m})$ away and returning to the seated position. The test, as the chair sit-and-reach and back scratch test, was measured on two occasions. Test-retest showed great significance among all participants $(I C C=.95 ; I C C=.98$ for men and $I C C=.90$ for women). All test-retest significance and test descriptions were taken from Rikli and Jones (2013).

Quality of Life Questionnaire by World Health Organization (WHOQOL-BREF). For the purpose of this study, World Health Organization questionnaire was used (WHOQOL-BREF), which was shorter version of WHOQOL-100 (World Health Organization, 2002). Twenty-four items from the original questionnaire were chosen, one from each domain which described the quality of life in general and for the overall health. So, the questionnaire was comprised of twenty-six items. As a result of WHOQOL-BREF questionnaire, quality of life profile was got which explained the quality of life through four domains: physical health, psychological health, social relationship and environment. The result in each domain was expressed as the average answers in items which described each domain. Items of general quality of life and general health were considered independent. Answers in each item were given on a Likert scale ranged from 1to 5, where 1 represented the lowest agreement with the individual item, and 5 represented the biggest agreement with the single item (Martinis, 2005). The answers were transformed on a scale from 0 to 20. According to Skevington, Lotfy and O'Connell (2004), the questionnaire showed great discriminant validity for each of the domains, and the most successful difference was between healthy and sick persons in physical and psychological health domains.

Statistical analysis. STATISTICA (Statsoft, Inc., Tulsa, OK. Version 10) was used for the statistical analysis. Descriptive statistics were calculated 
for all included variables. Differences between individual variable between active and non-active group were determined using Man-Withney $U$-test. Statistical significance was set at $p<.05$.

\section{RESULTS}

Kolmogorov-Smirnov test showed that data weren't normally distributed. Thirteen active female adults comprised $62 \%$ of total sample and non-active female adults $38 \%$. No statistically significant differences were obtained in physical measures between two groups $(p<.05)$ showed in table 1.

Table 1. Basic descriptive physical parameters (means \pm standard deviations)

\begin{tabular}{|l|l|l|}
\hline \multicolumn{1}{|c|}{ Variables } & \multicolumn{1}{c|}{ Active $(n=\mathbf{1 3})$} & Non-active $(n=\mathbf{8})$ \\
\hline Age (years) & $66.54 \pm 4.59$ & $71.81 \pm 7.15$ \\
\hline Height $(\mathrm{cm})$ & $158.08 \pm 5.35$ & $160.55 \pm 6.34$ \\
\hline Weight $(\mathrm{kg})$ & $75.47 \pm 13.52$ & $74.40 \pm 14.06$ \\
\hline BMI $\left(\mathrm{kg} / \mathrm{m}^{2}\right)$ & $30.18 \pm 0.49$ & $28.84 \pm 0.35$ \\
\hline
\end{tabular}

Note. $* p<.05$.

Results presented in Table 2 showed basic descriptive parameters and main differences between active and non-active female adults in SFT. As the tests measured two times, Cronbach's $\alpha$ showed great significance between two attempts (chair sit-and-reach test $\alpha=.99$; back scratch test $\alpha=.99$; 8-foot up-and-go test $\alpha=.98$ ). There were significant differences between four senior fitness tests: 30 -second arm curl test ( $p=.03$ ), 2-minute step test $(p=.00)$, chair sit-and-reach test $(p=.02)$ and 8-foot up-and-go test $(p=.01)$. Other tests showed no significant differences between the analyzed groups. Values in 30-second arm curl test also showed that active female adults had almost $23 \%$ better results than non-active group, also like in 2-minute step test (better results up to $45 \%$ ), chair sit-and-reach test (up to 134\%) and in 8-foot up-and-go test (up to $34 \%$ ).

Active and non-active female groups also showed differences between two out of four psychological domains represented in WHOQOLBREF questionnaire. The main differences were between psychological health $(p=.04)$ and environment $(p=.01)$, whether in other two domains the groups showed no statistical differences $(p>.05)$ (Table 3). No statistical differences were found between perception of quality of life and health satisfaction between non-active and active participants $(p>.05)$.

\section{DISCUSSION}

Aging, as part of the whole-life process, represents biological changes in people. Overall efficiency of doing everyday activities is decreasing primarily because of sedentary way of life and lack of physical activity. On the contrary, evidence from our study showed how people can improve physical activity or at least maintain physical performance and psychological health. Functional fitness performance enables people to perform normal everyday activities safely and independently without undue fatigue (Rikli and Jones, 2013).

\begin{tabular}{|l|c|c|}
\hline \multicolumn{1}{|c|}{ Variables } & Active $(n=\mathbf{1 3})$ & Non-active $(n=\mathbf{8})$ \\
\hline 30-second chair stand test (repetitions) & $17.77 \pm 4.34$ & $14.87 \pm 4.12$ \\
\hline 30-second arm curl test (repetitions) & $20.10 \pm 4.55^{*}$ & $15.5 \pm 4.17$ \\
\hline 2-minute step test (repetitions) & $83.77 \pm 16.97^{*}$ & $46.00 \pm 15.08$ \\
\hline Chair-sit-and-reach test (cm) & $5.75 \pm 7.84^{*}$ & $-1.97 \pm 5.60$ \\
\hline Back scratch test (cm) & $-6.83 \pm 9.85$ & $-1.28 \pm 11.79$ \\
\hline 8-foot up-and-go test (sec) & $5.60 \pm 0.59^{*}$ & $7.49 \pm 2.25$ \\
\hline
\end{tabular}

\begin{tabular}{|l|l|l|}
\hline \multicolumn{1}{|c|}{ Variables } & \multicolumn{1}{|c|}{ Active $(n=\mathbf{1 3})$} & Non-active $(n=\mathbf{8})$ \\
\hline Physical health domain & $17.63 \pm 2.26$ & $16.14 \pm 2.91$ \\
\hline Psychological health domain & $17.17 \pm 1.79^{*}$ & $14.92 \pm 2.89$ \\
\hline Social environment & $17.43 \pm 2.80$ & $15.67 \pm 2.83$ \\
\hline Environment & $18.81 \pm 1.31^{*}$ & $16.31 \pm 2.46$ \\
\hline
\end{tabular}

Table 2. Basic descriptive physiological parameters (means \pm standard deviations)

Note. ${ }^{*} p<.05$.

Table 3. Basic descriptive psychological parameters (means \pm standard deviations) 
Many independent older adults, often due to their sedentary lifestyles, function dangerously close to their maximum ability level during normal activities. Unfortunately, more than one-third of community-dwelling older adults are at risk for mobility problems and falls. It is generally known that physical activity is decreased during the period of aging and physical activity is associated with the maintenance or improvement of physical fitness (Dwyer \& Davis, 2005; Riebe et al., 2009).

Results showed that two groups differed in 30-second arm curl test, 2-minute step test, chair sit-and-reach test and 8-foot up-and-go test $(p<.05)$, when looking their fitness profile. In other fitness variables, no significant differences were found $(p>.05)$. This means that active older women who participated in our study had better aerobic endurance, upper body strength, lower body flexibility, agility and dynamic balance than non active older women.

In our study active women achieved significantly higher scores in upper body strength (30-seconds arm curl test) in comparison to nonactive group, probably because of the training program included in their everyday activities. In general, Bassey (1998) reported an average loss of upper-arm strength of $2 \%$ per year for women aged 65 years and older. Based on these findings, older men and women could lose between one-quarter and one-third of muscle strength over a 10 -year period, which would make a considerable impact on the quality of life and the ability to remain independent from other people. Also, elderly women lost $4 \%$ more strength in lower (14\%) compared to upper limbs (10\%) (Milanović et al., 2013). Decrease in muscle strength has been shown to relate with aging and muscle-mass loss, and also with more physical inactivity.

As in 30-second arm curl test, obtained scores on aerobic endurance (2-minute step test) also showed statistical differences among groups $(p<.05) . \mathrm{VO}_{2} \max$ is not constant through lifespan. According to American College of Sports Medicine (1998), $\mathrm{VO}_{2} \max$ decreases approximately 5 to $15 \%$ per decade beginning at 25-30 years of age. This decline in $\mathrm{VO}_{2}$ max can be attributed to age-related reductions in both maximal cardiac output and maximal arteriovenous oxygen (a-v O2) difference. Study showed that older persons could adapt to a program of regular aerobic training as well as their younger counterparts. Older adults can achieve the same 10 to $30 \%$ increase in $\mathrm{VO} 2 \mathrm{max}$ in response to endurance exercise training as young adults. Also, study showed that maximal heart rate $\left(\mathrm{HR}_{\max }\right)$ declined at a rate uninfluenced by exercise training or sex of approximately $3-5 \%$ per decade (Wiebe, Gledhill, Jamnik, \& Ferguson, 1999). As said before, physical activity improves overall fitness, and speaking about that cardiovascular fitness more specifically. Pate et al. (1995) recommended light- to moderate-intensity physical activity on a more frequent basis to optimise health, but that changes are insufficient for improving $\mathrm{VO}_{2}$ max.

Flexibility is important for maintaining good posture and reducing the risk of injuries and back problems. It is also critical for task of daily living such as tying shoes, kneeling down to pick up objects from the floor, putting on overhead garments and combing hair (Cicioglu, 2010). Scores in chair sit-and-reach test showed that active female adults had better flexibility range of motion than their non-active colleagues $(p<.05)$. In general, there are incidences in age-related changes in flexibility among men and women, where woman's flexibility deterioration starts earlier than in men (at the age of approximately 63 opposed to 73 years old in men) (Statkohostas, Little, Vandervoort, \& Paterson, 2012; Statkohostas, McDonald, Little, \& Paterson, 2013). Active group had better results $(+7.72 \mathrm{~cm})$ than non-active group, which indicates that physical activity had positive impacts on flexibility. However, significant differences were not found in the performance of back scratch test $(p>.05)$. Studies have shown improvements in back scratch performance after resistance training alone (Cavani, Mier, Musto, \& Tummers, 2002) and resistance-balanced programs (DiBrezzo, Shadden, Raybon, \& Powers, 2005). It means that regular physical activity has positive effects on flexibility, but, as mentioned before, differences were not found, perhaps because of the small number of subjects participated in the study.

Balance and agility are important for a number of common mobility tasks such as walking, negotiating curbs, climbing stairs and making quick movements needed to avoid hazards in environment (Cicioglu, 2010). Performance on the 8-foot up-to-go test between groups showed significant differences between them $(p<.05)$. Past evidence also indicated that performance on the 8 foot up-and-go test could discriminate among various functional categories in older adults and was responsive to changes resulting from increased levels of physical activity (Podsiadlo \& 
Richardson, 1991; Tinneti, Speechley, \& Ginter, 1988). Studies also showed that this test was an excellent discriminator of performance changes and could detect expected differences between highly active and inactive older adults. Results showed that the average 8 foot up and go test scores of highly active older people were considerably better than those of inactive group (Rikli \& Jones, 2001), which is similar to our results.

Although, there were no significant differences in the results on 30-second chair stand test, lower body strength is the main predictor of balance, physical performance and mobility. Results indicated that lower body strength decreased by $30-50 \%$ between ages of 50-70 years (American College of Sports Medicine, 1998).

There are many known psychological changes associated with planned and structured, habitual exercise (Berger, 1996) mainly in four broad areas: enhanced mood, stress reduction, more positive self-concept and higher quality of life. Results in our study confirmed that active female participants had better results on two out of four quality of life domains compared to non-active female participants: psychologicalhealthandenvironment.

In order to maximize psychological benefits of exercise some major requirements should be met (Berger, 1996). Exercise should be pleasant and enjoyable, aerobic (or should influence breathing patterns), closed, predictable and spatially certain; conducted at moderate intensity and in duration of at least 20-30 minutes. Also, there should be absence of interpersonal competition and exercise must be conducted on a regular basis. Active female participants in our study were involved in such recommended type of exercise on regular basis ( 2 times a week, 60 minutes, moderate intensity). They reported significantly higher levels of psychological health than non-active female participants and were also more pleased with their environment. Previous research have shown that this kind of exercise can have great impact on participant's mood alteration, especially short-term decreases in anxiety, depression, anger and fatigue as well as increased well-being, alertness, vigour, clear thinking and energy (Berger, 1996).Also, exercise can serve as stress management technique alowing participants time to relax after busy day, think and problem solve or just enjoy in experiencing body in movement (Berger at al., 2007). Physical activity can be related to participant's self-concept, self-esteem, self-efficacy, self-awareness and selfknowledge (Berger, 1996).
As health-enhancement and disease-prevention models of exercise suggest that through exercise participants can increase their vigour and vitality, decrease fatigue and improve mobility as well as prevent numerous diseases such as coronary artery disease, osteoporosis, obesity and cancer (Berger at al., 2007). Especially for older people, physical activity can pay important role in the prevention and management of chronic diseases, reduction of physical decline, maintaining functional ability and prevention of injuries (Cyarto, Moorhead, \& Brown, 2004; Singh, 2002). Although active life is considered necessary in order to retain and improve one's physical health, our study showed no significant difference in this domain or in the single question about health satisfaction between active and non-active older females.

When people stop working they can experience decrease in their social relationships and support due to the reduced number of people they meet on everyday basis. As they get older their children get more independent and many of their friends pass away, so it is easy to become socially isolated. Research conducted by Woolham, Daly and Hughes (2013) in the UK found that living alone, not enjoying life, needing help with personal care and not being in touch with people as often as one would like predicted loneliness among people aged 55 and over. This is why involving in some sort of organized physical activity can have important role in socialization for older adults. It can provide them opportunities to meet and socialize with people on a regular basis and possibly reduce isolation and feelings of loneliness. However, our study did not find significant difference in social relationships between active and non-active participants - both groups reported similar levels of satisfaction with their personal relationships, social support and sexual activity.

The significant difference was found in the scores of the environment scale, which suggested that active older women perceived their financial resources, home environment, health and social care, freedom, safety, security, transport as well as their participation in and opportunities for recreation and acquiring new information and skills better that those not involved in regular physical activity. The findings are not surprising if we consider some of the barriers to exercise older people often report (Berger et al. 2007; Schultzer $\&$ Graves, 2004): poor health, environment lacking exercise opportunities, lack of knowledge and 
understanding of the relationship between moderate exercise and health, lack of exercise companion, fear of being injured, lack of time and need to exercise, etc. Older people also tend to underrate their physical abilities, they believe that they are more active than they really are, exaggerate the dangers of physical activity and enrol in age related stereotypes (Berger et al., 2007).

\section{CONCLUSION}

According to World Health Organization, health represents overall physical, psychological and social well-being, not only the absence of disease or decrepitude. From the obtained results, overall fitness and psychological components were higher among active older female adults because they, along with everyday activities, participate in organized aerobic physical activities. Because of that, physical activity and being active prolonged the state of mental health and kept their conditioning abilities at such level that allowed them to overcome everyday barriers. Even though the process of aging is natural and inevitable, an adequate level of physical activity should slow down the loss of functional and physical abilities and help maintain a healthy way of life for elderly people.

\section{REFERENCES}

American College of Sports Medicine (ACSM) Position Stand. (1998). Exercise and physical activity for older adults. Medicine and Science in Sports and Exercise, 30, 992-1008.

Bassey, E. J. (1998). Longitudinal changes in selected physical capabilities: Muscle strength, flexibility and body size. Age \& Ageing, 27(3), 12-16.

Bath, P. A., \& Morgan, K. (1998). Customary physical activity and physical health outcomes in later life. Age \& Ageing, 27(3), 29-34.

Berger, B. G, Pargman, D., \& Weinberg, R. S. (2007). Foundations of exercise psychology. Fitness information technology. Morgantown, USA.

Berger, B. G. (1996). Psychological benefits of an active life style: What we know and what we need to know. Quest, 48, 330-353.

Blair, S. N., \& Wei, M. (2000). Sedentary habits, health, and function in older women and men. American Journal of Health Promotion, 15(1), 1-8.

Cavani, V., Mier, C. M., Musto, A. A., \& Tummers, N. (2002). Effects of a 6-week resistance-training program on a functional fitness of older adults. Journal of Aging and Physical Activity, 10, 443-452.

Charmaz, K. (1983). Loss of self: A fundamental form of suffering in the chronically ill. Sociology of Health and Illness, 5, 168-195.

Cicioglu, I. (2010). Assessment of physical fitness levels of elderly Turkish males over 60 years. Collegium Antropologicum, 34(4), 1323-1327.

Cyarto, E. V., Moorhead, G. E., \& Brown, W. J. (2004). Updating the evidence relating to physical activity intervention studies in older people. Journal of Science and Medicine in Sport, 7(1), 30-38.

Desrosier, J., Noreau, L., Robichaud, L., Fougeyrollas, P., Rochette, A., \& Viscogliosi, C. (2004). Validity of the assessment of life habits in older adults. Journal of Rehabilitation Medicine, 36, 177-182.
DiBrezzo, R., Shadden, B. B., Raybon, B. H., \& Powers, M. (2005). Exercise intervention designed to improve strength and dynamic balance among communitydwelling older adults. Journal of Aging and Physical Activity, 13(2), 198-209. PUBMED ID 15995265

Dipietro, L. (1996). The epidemiology of physical activity and physical function in older people. Medicine \& Science in Sports \& Exercise, 28, 596-600.

Dwyer, G. B., Davis, S. E. (2005). ACSM's healthrelated physical fitness assessment manual. Philadelphia: Lippincott Williams \& Wilkins.

Federal Interagency Forum on Aging-Related Statistics. (2010). Older Americans 2010 - Key indicators for wellbeing. Retrieved from http://www.nia.nih.gov/

Fougeyrollas. P., Noreau, L., Bergeron, H., Cloutier, R., Dion, S.A., \& St-Michel, G. (1998). Social consequences of long term impairments and disabilities: conceptual approach and assessment of handicap. International Journal of Rehabilitation Research, 21, 127-141.

Gauvin, L., \& Spence, J. C. (1996). Physical activity and psychological well-being: Knowledge base, current issues, and caveats. Nutrition. Reviewes, 54, 53-65.

Glass, T. A., Mendes de Leon, C., Marottoli, R. A., \& Berkman, L. F. (1999). Population based study of social and productive activities as predictors of survival among elderly Americans. BMJ, 319, 478-84.

Gorman, M. (1999). Development and the rights of older people. In Randel, J. et al. (Eds.) The ageing and development report: Poverty, independence and the world's older people (pp. 3-21), London, Earthscan Publications Ltd.

Horowitz, A., Reinhardt, J. P., Boerner, K., \& Travis, L. A. (2003). The influence of health, social support quality and rehabilitation on depression among disabled elders. Aging \& Mental Health, 7(5), 342-350.

Kaplan, R. M. (1994). The ziggy theorem: Toward an outcomes-focused health psychology. Health Psychology, 13, 451-460. 
Martinis, T. (2005). Quality of life perception in age functioning (Master's theses (in Croatian)). University of Zagreb.

Milanović, Z., Pantelić, S., Trajković, N., Sporiš, G., Kostić, R., \& James, N. (2013). Age-related decrease in physical activity and functional fitness among elderly men and women. Clinical Interventions in Aging, 8, 549-556.

Nelson, M. E., Rejeski, W. J., Blair, S. N., Duncan, P. W., Judge, J. O., King, A. C., ... Castaneda-Sceppa, C. (2007). Physical activity and public health in older adults: Recommendation from the American College of Sports Medicine and the American Heart Association. Medicine \& Science in Sports \& Exercise, 39, 14351445.

Pate, R. R., Pratt, M., Blair, S. N., Haskell, W. L., Macera, C. A., Bouchard, C., ... Wilmore, J. H. (1995). Physical activity and public health: A recommendation from the Centre for Disease Control and Prevention and the American College of Sports Medicine. Journal of the American Medical Association, 273, 402-407.

Pavot, W., \& Diener, E. (1993). Review of the Satisfaction with Life Scale. Psychological Assessment, 5, 164-172.

Pibernik-Okanović, M. (2001). Psychometric properties of the World Health Organization quality of life questionnaire (WHOQOL-100) in diabetic patients in Croatia. Diabetes Research and Clinical Practice, 51, 133-143.

Podsiadlo, D., \& Richardson, S. (1991). The timed "up \& go": A test of basic functional mobility for frail elderly persons. Journal of the American Geriatrics Society, 39, 142-148.

Rantanen, T., Era, P., \& Heikkinen, E. (1997). Physical activity and the changes in maximal isometric strength in men and women from the age of 75 to 80 years. Journal of the American Geriatrics Society, 45(12), 1439-1445.

Rejeski, W. J., \& Mihalko, S. L. (2001). Physical activity and quality of life in older adults. Journals of Gerontology Series A: Biological Sciences and Medical Sciences, 56, 23-35.

Riebe, D., Blissmer, B. J., Greaney, M. L., Garber, C. E., Lees, F. D., Clark, P. G. (2009). The relationship between obesity, physical activity and physical function in older adults. Journal of Aging and Health, 21(8), 1159-1178.

Rikli, R., \& Jones, J. (1999). Development and validation of a functional fitness test for community-residing older adults. Journal of Aging and Physical Activity, 7, 129-161. Rikli, R. , \& Jones, C. (2013). Senior fitness test manual ( $2^{\text {nd }}$ edition). Champaign, Il: Human Kinetics.
Schutzer, K. A., \& Graves, B. G. (2004). Barriers and motivations to exercise in older adults. Preventive Medicine, 39(5), 1056-1061.

Simonsick, E. M., Lafferty, M. E., Phillips, C. L., Kasl, S. V., Seeman, T. E., Fillenbaum, G., ... Lemke, J. H. (1993). Risk due to inactivity in physically capable older adults. American Journal of Public Health, 83, 1443-1450.

Singh, F. M. (2002). Exercise comes of age: Rationale and recommendations for a geriatric exercise prescription. Journals of Gerontology. Series A: Biological Sciences and Medical Sciences, 57(5), 262-282.

Skevington, S. M., Lotfy, M., \& O'Connell, K. A. (2004). The World Health Organisation's WHOQOL-BREF Quality of Life Assessment: Psychometric properties and results of the international field trial- A report from the WHOQOL Group. Quality of Life Research, 13(2), 299-310.

Spirduso, W. W., \& Cronin, L. (2001). Exercise doseresponse effects on quality of life and independent living in older adults. Medicine \& Science in Sports and Exercise, 33(6), 598-608.

Stathokostas, L., Little, R. M., Vandervoort, A. A., \& Paterson, D. H. (2012). Flexibility training and functional ability in older adults: A systematic review. Journal of Aging Research, 2012, 1-30.

Stathokostas, L., McDonald, M. W., Little, R. M. D., Paterson, D. H. (2013). Flexibility of older adults aged 55-86 years and the influence of physical activity. Journal of Aging Research, 2013, 743-843.

Taylor, A. H., Cable, N. T., Faulkner, G. E., Hillsdon, M., Narici, M., \& Van der Bij, A. K. (2004). Physical activity and older adults: A review of health benefits and theeffectiveness of interventions. Journal of Sports Sciences, 22, 703-725.

Tinetti, M., Speechley, N., \& Ginter, S. (1988). Risk factors for falls among elderly persons living in the community. New England Journal of Medicine, 319, 1701-1707.

U. S. Department of Health and Human Services. (1996). Physical activity and health. National Center for Chronic Disease Prevention and Health Promotion, The President's Council on Physical Fitness and Sports.

Wiebe, C. G., Gledhill, N., Jamnik, V. K., \& Ferguson, S. (1999). Exercise cardiac function in young through elderly endurance trained women. Medicine and Science in Sports and Exercise, 31, 684-691.

Woolham, J., Daly, G., \& Hughes, E. (2013). Loneliness amongst older people: Findings from a survey in Coventry, UK. Quality in Ageing and Older Adults, 14(3), 192-204. 